(a) OPEN ACCESS

For numbered affiliations see end of article.

\section{Correspondence to}

Dr Byron Crowe, Beth Israel Deaconess Medical Center, Boston, MA 02215, USA; bcrowe@bidmc.harvard.edu

Received 27 April 2021 Accepted 21 August 2021 Published Online First 11 September 2021

\section{Check for updates}

(c) Author(s) (or their employer(s)) 2022. Re-use permitted under CC BY-NC. No commercial re-use. See rights and permissions. Published by BMJ.

To cite: Crowe B, Gaulton IS, Minor N, et al. BMJ Qual Saf 2022;31:70-74.

\title{
To improve quality, leverage design
}

\author{
Byron Crowe (D) , 1,2 Jessica S Gaulton, ${ }^{3}$ Noah Minor, ${ }^{2}$ David A Asch, ${ }^{4}$ \\ Jeff Eyet, ${ }^{5}$ Erin Rainosek, ${ }^{6,7}$ Kristen Flint (1) , ${ }^{1}$ Joseph Joo, ${ }^{8}$ \\ Chip Chambers (D) , ${ }^{4}$ Sherry Bright, ${ }^{9}$ Julius J Yang, ${ }^{1}$ Gene Beyt, ${ }^{10}$ \\ Read Pierce, ${ }^{8}$ James M Moses (i) ${ }^{11,12}$
}

\section{THE INTERSECTION OF QUALITY IMPROVEMENT AND DESIGN THINKING}

The year was 1987, and a bold experiment was under way-the US-based National Demonstration Project in Quality Improvement in Health Care (NDP). This effort brought together 21 companies recognised for excellence in quality manufacturing with 21 healthcare organisations to test whether revolutionary practices from quality improvement (QI) could be applied to healthcare. The partnership succeeded and NDP was extended for another 3 years, eventually becoming the Institute for Healthcare Improvement. ${ }^{1}$ Since then, QI principles and methods have spread broadly across healthcare.

Around the same time the NDP was under way, another quiet revolution in systems thinking was taking shape in the emerging field of human-centred design. In 1988, Norman authored the landmark book 'The Design of Everyday Things', an explanation of how human-centred design-'an approach that puts human needs, capabilities, and behavior first, then designs to accommodate those needs, capabilities, and ways of behaving ${ }^{2}$ could dramatically improve products and services. Human-centred design methods, broadly referred to as design thinking (DT), are now widely used across diverse industries. ${ }^{3}$ Companies that have implemented design practices outperform their peers, ${ }^{4}$ and leading organisations like Google, Apple and General Electric use DT to create world-class products and services. $^{5}$

Although healthcare has invested heavily in systems improvement using QI, far fewer in healthcare are familiar with the improvement methodology of DT. A tremendous opportunity exists to further enhance contemporary healthcare improvement efforts by integrating the human-centred methods of DT that have revolutionised other industries. However, a knowledge gap remains on how to practically implement core methods from DT into QI practice.

Here we explain fundamental DT methods and how they can integrate into existing improvement efforts, providing a starting point for organisations and leaders to leverage this human-centred approach and harness the powerful emotional perspectives of 'users', the patients, families, caregivers and clinical team who interact with the healthcare system. In our own quality journeys, we have discovered the power of DT to elevate QI work and believe the time is now to bridge these two complementary disciplines, ushering in a new era of human-centred QI using the best parts of these two powerful methodologies.

\section{COMPARING DT AND QI}

DT is a methodology for solving complex problems. In that sense, DT is fundamentally similar to methodologies like Lean and total quality management in that it encompasses a set of core principles augmented by structured processes to achieve desired outcomes. ${ }^{67}$ The major difference is that DT methods are specifically designed to capture the human perspective in a system, generating deep insights into how users feel and act, identifying unmet emotional needs that drive behaviour and designing solutions directly addressing those needs. Moreover, DT methods foster dialogue and creativity among teams in powerful ways, leading to better alignment around the contribution of emotions and behaviours to systems issues and generating humancentred solutions.

In short, DT principles and methods are purpose built for understanding people, 
while QI principles and methods are purpose built for understanding the process. This is not to say one is better than the other, just that they are different in their focus and strengths. When applied together, they can be complementary and synergistic, creating balance between clinical and process goals and human emotions, forces that are commonly in tension in healthcare.

\section{HOW DT WORKS ALONGSIDE QI}

The methods and tools of DT and QI share many similarities and can be implemented alongside one another. At a high level, both disciplines have an overarching structure guiding improvement work. In QI, this is often the Model for Improvement (MFI) while in DT it is predominantly the Double Diamond (DD) model. ${ }^{8}$ Both MFI and DD are phased (but ultimately non-linear) approaches in which practitioners seek to understand and accurately define a complex problem, then generate and iteratively test solutions. In MFI, iterative testing is supported through Plan-DoStudy-Act (PDSA) cycles in which a process is manipulated and observed for improvements and learning; in DT, iterative testing occurs in the solutioning stages of the DD model and is supported through an emphasis on rapid prototyping of solutions with users. The phases of MFI and DD can be overlaid to create the combined method that we term 'human-centered QI' (figure 1A).

Similarly, both DT and QI approaches use specific tools to gain insight into system performance. In QI, common examples include process maps to visually represent discrete process steps or fishbone diagrams to highlight potential process failure points. In DT, commonly used tools include empathy maps to highlight the breadth of emotions experienced by a user (figure 1B) and user journeys to visually represent emotions experienced during process steps (figure 1C). Design tools often have a similar underlying purpose to many QI tools, but provide a human-centred lens through which to view a problem (table 1).

Below, we further describe the DD model, several key tools used in DT and provide an example using QI and DT together in a contemporary improvement project.

\section{THE DD MODEL}

The DD model is organised into four major stagesdiscover, define, develop and deliver. The two diamonds represent distinct periods of thinking-first to fully characterise the problem (discover, define), and then to craft human-centred solutions (develop, deliver). In the discovery and define periods, teams work to understand a process through the eyes of the user, conducting interviews and observations with users to generate insights about their behaviours and unmet needs and ultimately producing a shared problem definition. In DT, problems are often reframed as 'How

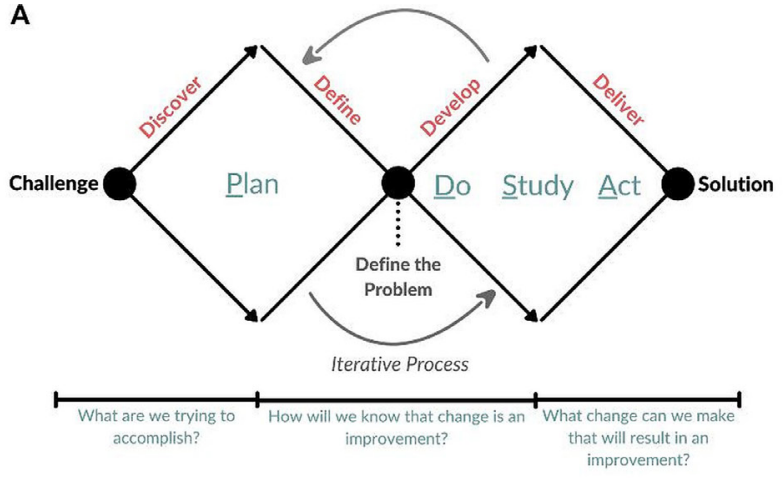
onto the Double Diamond model of design thinking to create the hybrid methodology that we term 'human centered QI'. (B) An empathy map is a tool to capture the breadth of behaviours and emotions experienced by a user and begin identifying pain points and potential gains from improvements to the current system. (C) A user journey provides a visual representation of process steps as experienced by a user, categorising each step as a net positive or negative emotional experience to better identify opportunities to address unmet needs. QI, quality improvement. The figure and table were both created by the authors.

might we...' statements that foster a creative exploration of the challenge. In the develop and deliver stages, teams leverage their prior insights about unmet human needs to craft innovative solutions that directly address those needs, cocreating with users and other stakeholders to develop and test solution prototypes in a rapid, iterative fashion to identify and learn from early failures.

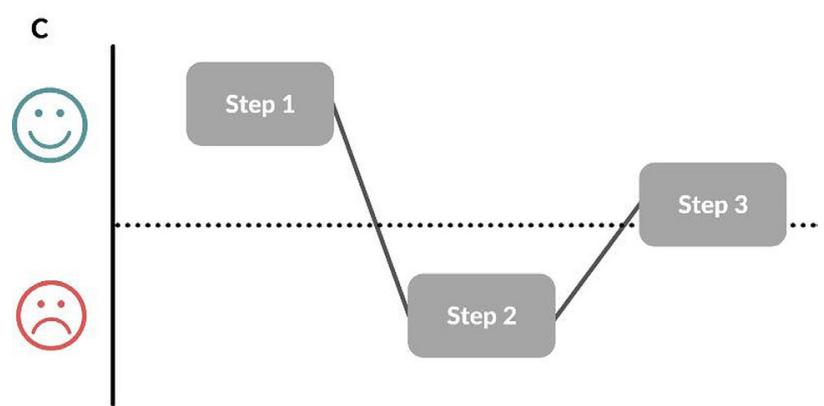


Table 1 QI and design tool integration

\begin{tabular}{|c|c|c|c|}
\hline Purpose in improvement work & QI tool & Design tool & Integration \\
\hline $\begin{array}{l}\text { Overarching structure guiding the } \\
\text { process }\end{array}$ & Model for Improvement & Double Diamond & $\begin{array}{l}\text { Apply 'Double Diamond' model of } \\
\text { diverging and converging thinking } \\
\text { to fuel PDSA, both to better define } \\
\text { the problem in a human-centred } \\
\text { way, create consensus among teams } \\
\text { on the true problem to solve, foster } \\
\text { greater creativity and faster tests of } \\
\text { change during solutioning and ensure } \\
\text { solutions are meeting a human need. }\end{array}$ \\
\hline Creating a problem definition & $\begin{array}{l}\text { Model for Improvement: } 3 \\
\text { fundamental questions }\end{array}$ & Value prop canvas & $\begin{array}{l}\text { Use the value prop canvas to clearly } \\
\text { define the benefits of solving a } \\
\text { problem for different stakeholders in } \\
\text { terms of jobs to be done, pains and } \\
\text { gains. }\end{array}$ \\
\hline
\end{tabular}

$\begin{array}{ll}\text { Understanding current process } & \text { Process map } \\ & \text { User journey } \\ \text { Understanding failure points } & \begin{array}{l}\text { Fishbone diagram, failure mode and Personas and empathy maps } \\ \text { effects analysis and Pareto charts }\end{array}\end{array}$

Apply user journeys alongside process maps to understand the emotions experienced by users during different process steps to define pain points, understand how pains might influence behaviour and identify unmet needs in the current system. effects analysis and Pareto charts

Generate user personas to understand the most typical users, their needs and common pain points. Use empathy maps to aid QI teams in deeply understanding user experiences, emotions and behaviours in the current process in relation to the ultimate goals.

\begin{tabular}{lll}
$\begin{array}{l}\text { Measuring for improvement } \\
\text { Statistical process control chart }\end{array}$ & 'Powerful Questions'testing & $\begin{array}{l}\text { Incorporate structured interviews to } \\
\text { capture early, directional feedback } \\
\text { on whether a new intervention is } \\
\text { meeting user needs. Detect important } \\
\text { failures before a measured process } \\
\text { deviation is apparent. }\end{array}$ \\
$\begin{array}{ll}\text { Rapid testing and learning } \\
\text { PDSA cycle }\end{array}$ & $\begin{array}{l}\text { Create low-fidelity versions of } \\
\text { solutions (prototypes), test them } \\
\text { with users to learn about feasibility/ } \\
\text { acceptability and use learnings and } \\
\text { failures to refine solutions. }\end{array}$ \\
$\begin{array}{l}\text { Gathering feedback for future tests } \\
\text { of change }\end{array}$ & Debrief/huddle & $\begin{array}{l}\text { Foster new cycles of improvement by } \\
\text { asking users and teams to creatively } \\
\text { reflect on the intervention in both } \\
\text { practical and aspirational terms. }\end{array}$ \\
\hline
\end{tabular}

QI, quality improvement.

The diamond shape itself represents a key design principle-'diverge, then converge'. In the diverging stages, teams capture and display as many ideas as possible without judgement, creating a psychologically safe space for creative exploration as all ideas are welcome. Once teams have 'diverged' in their thinking, they apply a more rigorous lens and 'converge' on a shared problem definition or chosen solution.

\section{APPLYING A HUMAN-CENTRED LENS}

Throughout the DD process, teams can employ many tools to generate insights into user emotions and unmet needs. Empathy maps and user journeys (figure 1B,C) are two design tools that merit special attention. Empathy maps enable teams to place themselves in a user's shoes when interacting with a system, categorising the experience into four domains: what users say, do, think and feel. Teams typically conduct design interviews with patients or other users, then fill out the empathy map to capture a holistic view of user experience. User journeys similarly provide a visual representation of the emotional components of a process by categorising each step as a net negative or positive experience for the user. Empathy maps and user journeys-like process maps and fishbone diagrams as used in QI-are foundational tools, and they can be applied immediately to strengthen existing QI initiatives with emotional frames that often drive 
behaviour but remain hidden. There are hundreds of additional design tools that can be used during projects, and resources exist to explore the full suite of both design and QI tools. ${ }^{910}$ Likewise, a useful series of case studies is available showing how healthcare organisations have implemented design in practice. ${ }^{11} 12$

\section{DESIGN IN ACTION: IMPROVING BREAST FEEDING IN THE NEONATAL INTENSIVE CARE UNIT}

Consider this real-world example with some extrapolated details illustrating how DT and QI tools were used together to improve breastfeeding support for mothers in a neonatal intensive care unit (NICU) at a major US health system.

NICU clinicians received feedback that some mothers were dissatisfied by not meeting key breastfeeding goals after discharge. This was surprising feedback because NICU mothers were routinely supported in pumping breast milk to maximise exclusive consumption of breast milk by infants in the first months of life, a practice that is widely recommended and a process that was seemingly performing well. An interdisciplinary team including a professional DT practitioner was convened to better understand current system performance using a 'humancentered QI' approach combining QI and DT methods.

The team initiated the DD framework by 'diverging' to understand the problem and generate insights. The team conducted human-centred design interviews with NICU mothers, caregivers and providers, filled out empathy maps and user journeys and created a process map and fishbone diagram to understand clinical workflow. The DT tools quickly revealed how the human side of this process was leading to failure. In the design interviews, mothers overwhelmingly wanted to establish feeding at the breast as early as possible, but it was often initiated much later than desired.

The key human insight was that the provider and the mothers' definitions of 'success' differed, leading to process failure. NICU clinicians felt the current system was performing well if infants were receiving breast milk, even if pumped, in line with current guidelines. In contrast, mothers expressed an unmet need to bond with their infant through feeding at the breast and felt disappointed when not supported in that experience earlier in the NICU, a finding of additional clinical importance as mothers who do not feed at the breast are at higher risk of discontinuing the optimal practice of exclusive breast milk feeding. The team subsequently 'converged' on a shared problem definition and crafted both a design challenge statement and QI aim statement: 'How might we better support a mother's breastfeeding experience in the NICU?' and 'We aim to increase the rate of feeding at the breast among first time mothers in the NICU from $33 \%$ to $50 \%$ within 6 months of starting the project'.

The team diverged again by hosting multiple designbased ideation sessions with patients, providers and staff to generate solutions, eventually converging on the idea of creating a team of NICU nurses with dedicated time to assist mothers with breast feeding each shift. The team created process, outcome and balancing measures to track progress, and over the course of 6 months conducted six PDSA cycles involving multiple prototype iterations. Feedback from patients and providers was captured using a 'Powerful Questions' approach, a structured design tool using standardised questioning to understand acceptability of a new innovation and guide prototype refinement. Over the course of the testing phase, the team observed a statistically significant increase in rates of feeding at the breast using a statistical process control chart.

\section{TOWARDS A NEW ERA OF HUMAN-CENTRED QI}

Design methods can be applied systematically alongside existing QI work, and we suggest QI practitioners can greatly benefit from incorporating DT methods. Even though QI and DT have grown in parallel and both had enormous impact, only one has been enthusiastically adopted across healthcare. We are not the first to suggest that DT and other 'person centered' methods such as cocreation be used in healthcare improvement. ${ }^{1314}$ Others have put forward excellent frameworks for when organisations might deploy these methods, including which methods might be most appropriate for creating new innovations versus improving existing processes. ${ }^{15} 16$ Early adopters like Kaiser Permanente and the Mayo Clinic have already integrated DT into major projects. ${ }^{12} 17$ However, knowledge of how to actually use DT to improve healthcare systems is limited despite DT's success in other industries, a state similar to QI in its early days of adoption. ${ }^{18}$ Although organisations may be concerned by the burdens and challenges of implementing and scaling a new methodology, DT resources and training are widely available, and organisations can draw on the experience of early healthcare adopters and other industries to learn how DT has been deployed within large organisations. In our experience, DT methods are conceptually easy to understand and can be learnt quickly, especially by those with prior experience in systems improvement. Many organisations already train staff in QI, and DT curricula can be integrated within existing training infrastructures.

By using design to create a new era of human-centred QI, we can harness a powerful method for improvement by deepening our understanding of human needs, accelerating change efforts and imbuing new meaning and joy in work by bringing people back to the centre of care.

\footnotetext{
Author affiliations

${ }^{1}$ Department of Medicine, Beth Israel Deaconess Medical Center, Boston, Massachusetts, USA

${ }^{2}$ Department of Medicine, University of Colorado-Anschutz Medical Campus, Aurora, Colorado, USA

${ }^{3}$ Abington Hospital - Jefferson Health, Abington, Pennsylvania, USA

${ }^{4}$ University of Pennsylvania Perelman School of Medicine, Philadelphia,

Pennsylvania, USA

${ }^{5}$ University of California Berkeley Haas School of Business, Berkeley, California, USA
} 
${ }^{6}$ Department of Pediatrics, Yale School of Medicine, New Haven, Connecticut, USA

${ }^{7}$ Department of Pediatrics, Mayo Clinic, Rochester, Minnesota, USA

${ }^{8}$ Department of Internal Medicine, Dell Medical School at the University of Texas at Austin, Austin, Texas, USA

${ }^{9}$ Bright Strategies, Fruita, Colorado, USA

${ }^{10}$ Tulane University School of Public Health and Tropical Medicine, New Orleans, Louisiana, USA

${ }^{11}$ Boston Medical Center, Boston, Massachusetts, USA

${ }^{12}$ Spectrum Health, Grand Rapids, Michigan, USA

Twitter Byron Crowe @byrondcrowe, Jessica S Gaulton @jessgaulton and Erin Rainosek @erin_rainosek

Contributors BC and JM conceived the manuscript. BC, JG, NM and JM drafted the manuscript. BC, ER, GB, JG, NM, DAA, JE, JM, JJ, JJY and RP contributed to the discussion of design thinking principles. BC, CC, DAA, JG, JJ, JM, KF, $\mathrm{NM}, \mathrm{RP}$ and $\mathrm{SB}$ contributed to the integration of design and QI tools and the case study. All authors provided important intellectual content regarding the intersection of QI and design methods and critically revised the manuscript.

Funding The authors have not declared a specific grant for this research from any funding agency in the public, commercial or not-for-profit sectors.

Competing interests BC, ER and JE are co-founders of the non-profit Healthcare by Design.

Patient consent for publication Not required.

Provenance and peer review Not commissioned; externally peer reviewed.

Open access This is an open access article distributed in accordance with the Creative Commons Attribution Non Commercial (CC BY-NC 4.0) license, which permits others to distribute, remix, adapt, build upon this work noncommercially, and license their derivative works on different terms, provided the original work is properly cited, appropriate credit is given, any changes made indicated, and the use is noncommercial. See: http://creativecommons.org/licenses/by-nc/4. $0 /$.

\section{ORCID iDs}

Byron Crowe http://orcid.org/0000-0001-9217-1533

Kristen Flint http://orcid.org/0000-0001-6941-9385

Chip Chambers http://orcid.org/0000-0002-9293-9706

James M Moses http://orcid.org/0000-0002-5366-7816

\section{REFERENCES}

1 Godfrey AB. Quality health care. Qual Manag 1996 https:// www.qualitydigest.com/sep96/health.html
2 Norman D. The design of everyday things: revised and expanded edition. Basic Books, 2013.

3 Liedtka J. Why design thinking works. Harv Bus Rev 2018 https://hbr.org/2018/09/why-design-thinking-works

4 Sheppard B, Sarrazin H, Kouyoumjian G. The business value of design. McKinsey Q 2018.

5 Rae J. Design value index exemplars outperform the S\&P 500 index (again) and a new crop of design leaders emerge, 2016. Available: https://www.dmi.org/page/2015DVIandOTW/2015dmiDesign-Value-Index-Results-and-Commentary.htm

6 Young TP, McClean SI. A critical look at lean thinking in healthcare. Qual Saf Health Care 2008;17:382-6.

7 American Society for Quality. What is total quality management (TQM)? Available: https://asq.org/qualityresources/total-quality-management

8 UK Design Council. The double diamond: a universally accepted depiction of the design process. Available: https:// www.designcouncil.org.uk/news-opinion/double-diamonduniversally-accepted-depiction-design-process

9 Lewrick M, Link P, Leifer LJ. The design thinking toolbox: a guide to mastering the most popular and valuable innovation methods. John Wiley \& Sons, Inc, 2020.

10 Langley GJ. The improvement guide: a practical approach to enhancing organizational performance. Jossey-Bass, 2009.

$11 \mathrm{Ku} \mathrm{B}$, Lupton E. Health design thinking: creating products and services for better health. The MIT Press, 2020.

12 Mayo Clinic. Mayo clinic center for innovation: sample projects. Available: http://centerforinnovation.mayo.edu/ portfolio-2/

13 Batalden M, Batalden P, Margolis P, et al. Coproduction of healthcare service. BMJ Qual Saf 2016;25:509-17.

14 Elwyn G, Nelson E, Hager A, et al. Coproduction: when users define quality. BMJ Qual Saf 2020;29:711-6.

15 Roberts JP, Fisher TR, Trowbridge MJ, et al. A design thinking framework for healthcare management and innovation. Healthc 2016;4:11-14.

16 Bhattacharyya O, Blumenthal D, Stoddard R, et al. Redesigning care: adapting new improvement methods to achieve person-centred care. BMJ Qual Saf 2019;28:242-8.

17 McCreary L. Kaiser Permanente's innovation on the front lines. Harv Bus Rev 2010;88:92, 94-7, 126.

18 Batalden PB, Davidoff F. What is "quality improvement" and how can it transform healthcare? Qual Saf Health Care 2007;16:2-3. 